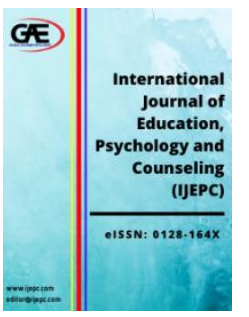

\author{
INTERNATIONAL JOURNAL OF \\ EDUCATION, PSYCHOLOGY \\ AND COUNSELLING \\ (IJEPC) \\ www.ijepc.com
}

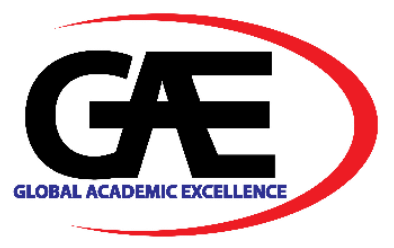

\title{
THE ROLE OF INTIMACY, BELONGING, SELF-ESTEEM INTHE ASSOCIATION BETWEEN ANXIOUS, AVOIDANT ATTACHMENT AND FORGIVENESS AMONG MARRIED IRANIAN WOMEN
}

\author{
Farahmand Elaheh ${ }^{1}$, Mariani MD Nor*2, Ghanbari Baghestan Abbas ${ }^{3}$, Mahmoud Danaee ${ }^{4}$
}

1 Department of Educational Psychology and Counselling, Faculty of Education, University of Malaya, 50603,

Kuala Lumpur, Malaysia

Email: elaheh.farahmand@siswa.um.edu.my

2 Department of Educational Psychology and Counselling, Faculty of Education, University of Malaya, 50603,

Kuala Lumpur, Malaysia

Email: marianin@um.edu.my

3 Department of Communication, Faculty of Social Science, University of Tehran (UT), Tehran, Iran

Email: ghanbari.abbas@ut.ac.ir

4 Department of Social Preventive Medicine, Faculty of Medicine, University of Malaya, 50603 Kuala Lumpur,

Malaysia

Email:mdanaee@um.edu.my

* Corresponding Author

\section{Article Info:}

\section{Article history:}

Received date: 19.04 .2021

Revised date: 05.05.2021

Accepted date: 15.05.2021

Published date: 25.06.2021

To cite this document:

Elaheh, F., MD Nor, M., Abbas, G. B., \& Danaee, M. (2021). The Role Of Intimacy, Belonging, Self-Esteem In the Association Between Anxious, Avoidant Attachment And Forgiveness Among Married Iranian Women. International Journal of
Abstract:

This study focuses on examining the mediating effect of intimacy, belonging, self-esteem on the relationships between anxious, avoidant attachment and forgiveness among Iranian married women. Data were collected from 435 women and the Partial Least Squares (PLS-SEM) method was applied to analyse the data. The results revealed that the impacts of anxious and avoidant attachment on forgiveness were meaningful. Also, empirical evidence was found for the mediating role of intimacy, belonging, and self-esteem on the relationship between avoidant attachment and forgiveness and also belonging and self-esteem on the relationship between anxious attachment and forgiveness. Results of this study suggest that the most accurate model of the relationship between attachment, intimacy, belonging, self-esteem, and forgiveness involves evaluating direct indirect effects. Marriage counselors and therapists can use these results to gain a deeper understanding of the foundations of marital life in Iran in terms of psychoeducational and therapeutic interventions. 


\author{
Education, Psychology and Keywords: \\ Counseling, 6 (40), 74-92 \\ DOI: $10.35631 / \mathrm{IJEPC} .640006$. \\ Anxious Attachment, Avoidant Attachment, Forgiveness, Belonging, \\ Intimacy, Self-Esteem
}

This work is licensed under CC BY 4.0

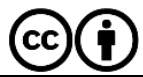

\title{
Introduction
}

In the last few years, there have been a rise of fascination in the effects of forgiveness in a relational bond. In family and couple therapy scope, forgiveness is a new essential debate. Recently psychologists in different areas such as personality, clinical, developmental have more attention to forgiveness. The growing number of publications focusing on forgiveness shows that forgiveness being increasing as a psychological construct (Askari, 2016). Forgiveness is a behaviour system that allows people to ease the stress and negative consequences that might arise because of interpersonal transgressions and encourages relationship preservation.

According to (Toussaint, Worthington, Williams, \& Webb, 2019) there is a positive relationship between forgiveness and a multitude of positive physical and mental health results, such as the reduction stress replies, decrease resting heart rhythm, and more life satisfaction. Even though compromise is not the sole purpose, forgiveness additionally has a positive effect on the relationship behaving, such as enhanced commitment (Riek \& Mania, 2012), recognized relationship value, and relational satisfaction (Braithwaite, Selby, \& Fincham, 2011). Therefore, insight into the factors that may be supported or impede forgiveness after a misbehaviour is a useful goal (Hirst, Hepper, \& Tenenbaum, 2019).

Scholars have revealed, better emotional and relational health is related to forgiveness (Worthington \& Sandage, 2016). Much of the current literature pays particular attention to forgiveness as a factor to promote closeness and trust and interrupt the damaging patterns of avoidance and retaliation (Bono, McCullough, \& Root, 2008;. Fincham \& Beach, 2002; Wieselquist, 2009). Consequently, one of the valuable aspects of an intimate relationship is forgiveness. Theoretically, forgiving is a transformational technique in which curing from past injustices takes place, and it is frequently a very significant aspect of couple therapy diverse from tolerating, excusing, or denying previous wrongdoings, (Fincham, Hall, \& Beach, 2006).

In this framework, the main theory is attachment theory, that is based on the connection that develops between child and caregiver and the implications this has for the child's developing self-concept and improving point of view of the social world. This theory will play key role mainly because the attachment is not limited to childhood (J Bowlby, 1982; John Bowlby, 1977, 1980). In that regard, Bowlby suggests that the infancy attachment affects 'the consequent capacity to make it to emotional bonds', while at the same time an entire range of adult dysfunctions involving 'marital problem and trouble with children as well as neurotic signs and personality disorders (John Bowlby, 1977).

Attachment construct theorized as one of the numerous characteristic styles and contains a secure attachment and insecure, anxious attachment and avoidant attachment (Ainsworth, Blehar, Waters, \& Wall, 1978). The individual with high avoidant attachment has a desire to see people undependable and unreliable on the other hand anxious attachment individual with 


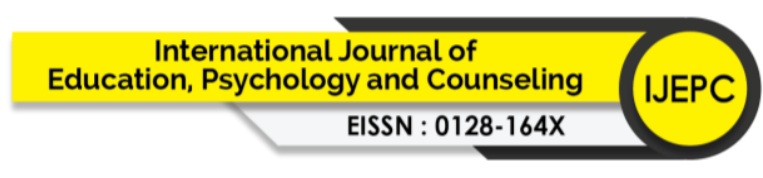

Volume 6 Issue 40 (June 2021) PP. 74-92

DOI 10.35631/IJEPC.640006

high levels of attachment anxiety with high attachment anxiety see themselves as the unlovely person (Bartholomew,1990; Bartholomew \& Horowitz, 1991). As the importance of these opinions of self and others, individuals with a high level of attachment avoidant have a desire to be unavailable to other people to avoid suffering from rejection and struggle (Feeney \& Karantzas, 2017).

\section{Literature Review}

\section{Attachment And Intimacy}

The link between insecure attachment styles to a variety of relationship problems that arise across connection between contexts has been explored by many investigators, including friendships and romantic relationships. Insecure attachment style (anxious and avoidant) are described by high dissatisfaction with partners and low expectation and trust in others (Chen, Colón, \& Barrow, 2020). A number of studies have realized that attachment predicts success and failure in a relationship. Secure attachment is linked to higher trust and responsibility (Simpson \& Rholes, 2017), better intimacy (Pielage, Luteijn, \& Arrindell, 2005), elevated selfconfidence, better communication skills (Guerrero, 1996), and a higher tendency for selfdisclosure (Sampthirao, 2016). The fundamental features of secure attachment style are positive attitudes toward others and self-esteem, whereas the significant characteristics of avoidant attachment style are negative views in the direction of others and lack of self-esteem, intimacy and distrusting others (Ainsworth, 1978b; Bartholomew \& Horowitz, 1991). These features, which are called positive and negative working models, generate the context of fulfilment and unfulfillment in social relationships.

Basically, secure attachment style with a positive approach and confidence in self and others, reduce the relationship between the fear of intimacy and unfulfillment in the relationship. Avoidant attachment style with a pessimistic mindset and mistrust in self and others raises the connection between fear of intimacy and unfulfillment in marriage. To put it another way, avoidance of intimacy and avoiding others that are the features of avoidant bonded people, are significant parts of unfulfillment in marriage. Thus, the avoidant attachment can strengthen the negative impacts of fear of intimacy on unfulfillment in marriage.

Gulzar (2018) pointed out that there is a correlation between insecure attachment and fear of intimacy. Fear of intimacy is a feature of anxious-ambivalent and avoidant people. Anxious ambivalent bonded people are aware of this fear, but avoidant people deny the existence of the fear since they perceive themselves as detached and independent. Attachment insecurity affects people's capability of starting intimacy and dependence with a romantic spouse, which probably intervene with the capability of becoming thoroughly invested in a long-term relationship, and to influence the notions of costs of ending the relationship.

\section{Attachment, Belonging And Self-Esteem}

Abraham H. Maslow pointed out in one of his well-known books that individuals "who have already been manufactured in the secure and powerful in the very first years, are more likely to remain secure and powerful afterwards in the challenge of all that threatens" (Maslow, 1943). Between the Maslow model of the hierarchy of needs and attachment theory are similarities (Bowlby, 1982; Bowlby, 1969). More specifically, attachment security is equivalent to the satisfaction of the esteem-needs and belonging in Maslow's hierarchy (Otway $\&$ Carnelley, 2013). Based on attachment research the feeling of attachment security 


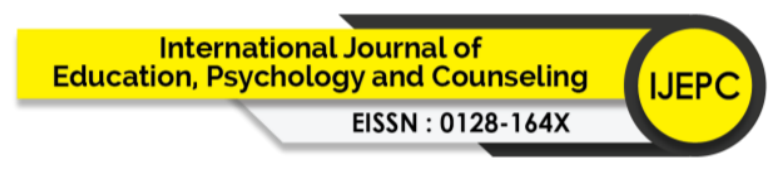

Volume 6 Issue 40 (June 2021) PP. 74-92

DOI 10.35631/IJEPC.640006

substantially affects subjective well-being, influence regulation and boost self- esteem and positive self-perception and well-amended interpersonal cognitions and responses (Collins \& Allard, 2001; Mikulincer \& Florian, 2001). The need to feel secure is theoretically comparable to the need to have a sense of belonging and safety, as described by Maslow (Otway \& Carnelley, 2013). In addition, Maslow pointed out that people who were receivers of respect (esteem) and love (belonging) in the past can more easily reach the point of personal growth and self-sufficiency (Maslow, 1970).

Maslow (1943) suggested that satisfaction of the belongings and esteem- or attachment-needs are prerequisites for the person's push in the direction of self-actualization and personal growth.

It is difficult for insecurely attached people to attain self-actualization because insecure feelings distract them (Otway \& Carnelley, 2013). Secure people are expected to be able to go beyond the self, better.

From a developmental perspective, whether caregivers consistently, regularly, and delicately satisfy the needs of their children may perhaps affect the growth of secure working attachment models among children. If the primary caregiver (i.e., mother) does not constantly and sympathetically respond to the needs of the children (i.e., lack of care), the children may form outlooks that they are more expected to be rejected when they ask for support or acceptance from others. Therefore, they tend to be more anxious about expressing their needs to important people in their lives and wakeful for rejection-relevant cues (Downey \& Feldman, 1996). A Combination of Maslow's (1943) theory and attachment theory implies that unsatisfied belonging - and safety -needs (attachment insecurity) probably refrain an individual from improving up the motivational hierarchy to their esteem-needs (self- liking and selfcompetence), partially due to incapability of these people to become involved in ideal examination.

Self-esteem challenges can generate self-doubt, increasing personal concerns that distract the individual from understanding and reacting to a partner's anxiety. However, security priming may strengthen self-esteem and decrease self-focused fears and worries that constrain support provision. Consequently, an individual facing self-esteem challenge might still be cable off and determined to supply haven support in response to a partner's need despite the presence of challenge. According to the study of (Mikulincer, Shaver, Bar-On, \& Sahdra, 2014), secure romantic attachment to the present partner was put into effect as experiencing low amounts of attachment-related avoidance and anxiety, both of which contributed separately to the mediation impacts. Previous studies propose that attachment-related anxiety is connected to inappropriate interpersonal behaviours, including being less responsive and supplying less instrumental support (Collins \& Feeney, 2000). As a result, when anxious attachment to the present partner is formed due to low self-esteem, low self-esteem might consequently result in poor caregiving, influencing the partner's fulfilment with the relationship. Additionally, when attachment-related avoidance is formed due to low self-esteem, interpersonal proximity with the current partner might be limited by low self-esteem people to defend themselves from being hurt due to rejection (Murray \& Holmes, 2008), which could reduce the partner's connection fulfilment. 


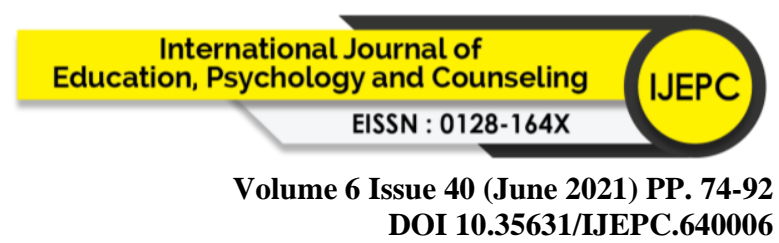

\section{Attachment And Forgiveness}

A strong predictor for recognizing when and why people may react to a transgression with forgiveness is attachment theory, due to the fact that not only is it basic to our understanding of how we are negotiating human relationships, but also foresees state variables related with forgiveness (Hirst et al., 2019). Many scholars hold the view that attachment and forgiveness are similar concepts, and attachment is the most reliable forecaster of forgiveness (Burnette et al., 2009; Chung \& Lee, 2014; Langman \& Chung, 2013).

On the other hand, individuals classified with a secure attachment style account greater amounts of forgiveness throughout a diverse range of the conclusions. Securely attached adults need a more extraordinary ability to use and adjust their emotions. This could contribute to the enhanced relationships and can be forecast of secure attachment (Burnette et al., 2009).

\section{Intimacy And Forgiveness}

The intimacy is from the reinforce the basics of the couples' love, as well as the forgiveness is necessary in order to control the couples' battle and disagreement and the staying dynamics of their love (Amani, Sohrabi, Bagheri, \& Nasisi Hains, 2017). Intimacy and relationship proximity is among the strongest predictors of transgression-specific forgiveness (Fehr, Gelfand, \& Nag, 2010). The positive influence of proximity on forgiveness has been investigated in romantic and a number of other kinds of adult relationships (Wazid \& Shahnawaz, 2017).

A transgression accounts for a betrayal of trust. However, trust is more easily restored in proximate relationships, not simply because proximity and trust are possibly synonymous. In other words, proximate relationships can make a shield against the impacts of transgressions. Victims in marital relationships can refer to a mutual history that allows them to discount their partner's misbehaviours. Intimate offenders themselves are more motivated to behave in approaches that inhibit the hurtfulness of their actions. Overall, there seems to be some evidence to indicate that different sources of information allow intimate victims to keep the view that their wrongdoer's partner is still truthful, more so than those victims who are not close to their wrongdoers (Strelan, Karremans, \& Krieg, 2017).

\section{Belonging And Forgiveness}

Forgiveness in the world that building a new social connection is not easy or possible might be a resource for restoring intimacy (Richman \& Leary, 2009). With this line of consciousness, it seems reasonable to assume a positive relationship between the need to belong and forgiveness, such that people who have an intense craving for belongingness determine a higher likelihood of spreading forgiveness to offenders than those whose need to belong is less noticeable.

The notion that a positive relationship between the need to belong and forgiveness must happen appears to be instinctive. However, in the psychological research, experimental support for such a relation is lacking, and the present study on the related topics suggests that the need to belong might make preservative connections that have been damaged by transgressions particularly difficult and doubtful (Barnes, Carvallo, Brown, \& Osterman, 2010).

Further investigations are required to provide greater insight into the effects of belongingness and forgiveness with individual happiness and satisfaction. Satici \& Tekin, (2016) examined that a sense of belonging theoretically is leading to contentment. 


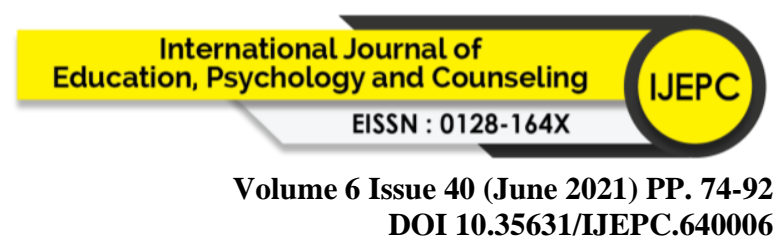

\section{Self-Esteem And Forgiveness}

Self-esteem specified as the positive and negative methods that a person's shows regarding self. In brief, it could be argued that self-esteem is collected from an individual's emotions concerning the concept of self (Orth \& Robins, 2019). When the issue is reflected in the framework of this study, it can be highlighted that the forgiveness tendency of individuals with high or low self-esteem may be different. Several lines of evidence suggest that since low selfesteem, individuals there might be more negative insights about themselves, so they have a lower tendency to forgive others and themselves. However, higher self-esteem people may have a higher tendency to forgive themselves and other individuals (Hong et al., 2020). Traditionally, it has been argued that studies in this regard show that self-esteem is connected with forgiveness (Yalcin, Kavakli, \& Kesici, 2017). Thus, self-esteem has a substantial positive impact on forgiveness people with a greater level of self-esteem are more able to forgive themselves and others. Self-esteem is one essential build that has demonstrated its important consequences to comprehend the self-forgiveness (Tiwari, Pandey, Parihar, \& Rai, 2020).

\section{Present Study}

In this study, we investigated the role of working models of attachment in forgiveness by examining the notion that intimacy and belonging and self-esteem mediate the link between attachment and forgiveness. To our knowledge, this represents the first attempt to explore intimacy, belonging and self-esteem as mediators between attachment and forgiveness. We generated the following hypotheses for this investigation: (a). Belonging mediates the relationship between anxious and avoidant attachment and forgiveness (b) Intimacy mediate the relationship between anxious and avoidant attachment and forgiveness (c) self-esteem mediates the relationship between anxious and avoidant attachment and forgiveness.

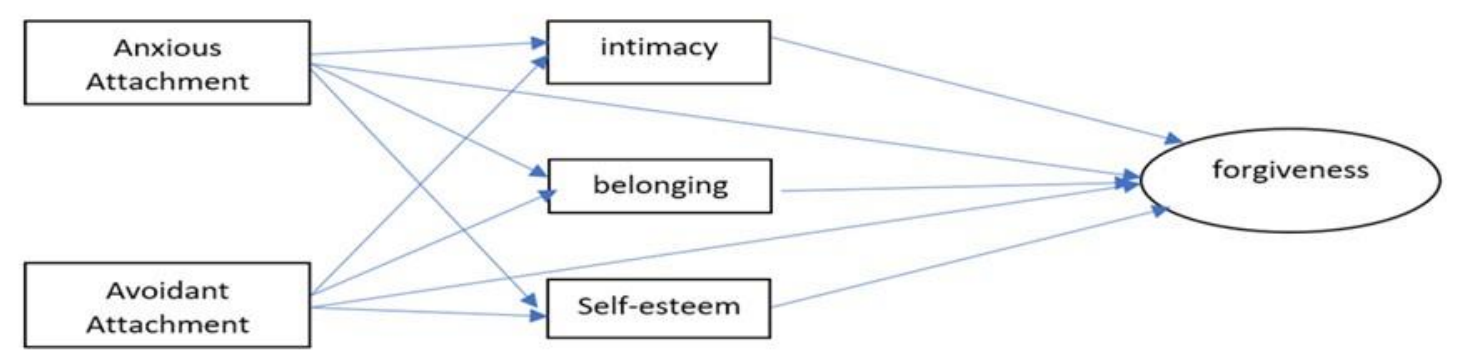

Figure1. Conceptual Framework

\section{Method}

\section{Research Design}

This study is solely quantitative throughout nature. More precisely, it is a cross-sectional survey design study that is supported by the post-positivism worldview theories (Creswell 2012) and focuses on Iranian married women marital satisfaction.

\section{Analytic Procedure}

In accordance with the instructions suggested by the (Henseler, 2018) considering that the research was predictive-explanatory, Partial Least Squares Structural Equation Modelling (PLS-SEM) was chosen as the method of analysis. Especially, the prediction errors, forecasting 


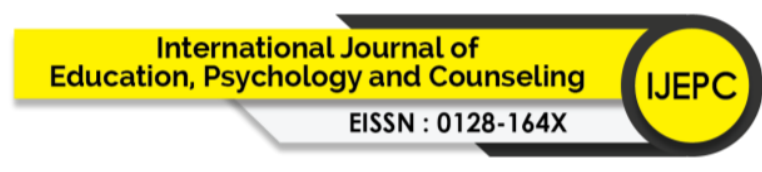

Volume 6 Issue 40 (June 2021) PP. 74-92

DOI 10.35631/IJEPC.640006

the importance of the effects, endogenous variables' $\mathrm{R}^{2}$, the statistical assumption of path coefficients were largely in focus.

\section{Population and Sampling}

In this study, all married women who come to counseling centres in the Mashhad megacity are considered as population. Data were collected from 435 Iranian women. The researcher chooses the multistage sampling method: in the first stage stratified sampling method was applied by selecting 13 districts of Mashhad, in the second stage a cluster sampling was used, and average 4 centres were selected randomly from each district and in the last stage in each centre simple random sampling was applied for data collection. The data collection was conducted by the researcher at the selected counseling centres in the city of Mashhad. The whole procedures of the data collection were with the permission of respected authorities in the city of Mashhad, including the Students' affair organization of the Ministry of Science, Research and Technology (MSRT) and State Welfare Organization.

\section{Measure}

\section{Anxious and Avoidant Attachment}

Experience in Close Relationship-revised is the 36-item questionnaire that has been used to assess contributors' anxiety and avoidant style. The ECR-R contains an 18-item scale that assesses anxious attachment (example: "I worry about being abandoned") and an 18-item scale that calculates avoidant attachment (example: "I prefer not to show a partner how I feel deep down'). Each item has a 7-point Likert scale with answers ranging from $1=$ strongly disagree to $7=$ strongly agree - experiences in Close Relationships (ECR) developed by. The scale contains two components that are measuring anxiety and avoidance, respectively. This questionnaire applied on 391 married Iranian individual which selected from different region of Tehran. Cronbach's alpha reported in all four subscales $0 / 89$.

\section{Forgiveness}

The Trait Forgivingness Scale (TFS) is including 10-item; it was used to evaluate forgivingness. The sample of item are "I can usually forgive and forget an insult,",". Applicants assess their agreement with every element ranging from 1 (strongly disagree) to 5 (strongly agree) (Berry, Worthington, O’Connor, Parrott, \& Wade, 2005). This questionnaire was adopted from (Khojasteh \& Koraei, 2010). This questioner applied on 245 males and 247 females among parents of high school student in Ahvaz. Cronbach's alpha reported in all four subscales $0 / 79$.

\section{Intimacy}

For assessing Intimacy between partners, a revised edition of the Intimacy Scale created by (Walker \& Thompson, 1983) was used. The scale ranged from 1(never) to 7(always), contained 17 items, the sample item was "We want to spend time together" The score is achieved by adding the scores of items and dividing them by 17 . The score is from 1 to 7 , and a higher score shows a higher intimacy level. The Intimacy scale first time was translated and validated in Iran by Sanai in 2000.

\section{Self-Esteem}

Contributors' self-esteem has been evaluated with the 10-item Rosenberg Self-Esteem Scale (Rosenberg, 1965)' self- esteem, which it has previously been linked with social inclusion. The 


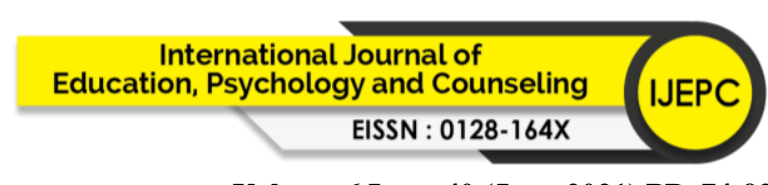

Volume 6 Issue 40 (June 2021) PP. 74-92

DOI 10.35631/IJEPC.640006

RSE demonstrated exceptional reliability in this sample $(a=0.77)$. Amount of agreement with each declaration encompassed on the RSE (e.g., "I feel that I'm a person of worth, was assessed using a scale ranging from 1 (strongly disagree) to 7 (strongly agree). This questionnaire was adopted from (Shapurian, Hojat, \& Nayerahmadi, 1987). The samples were collected from Iranian college students separately and consist of 232 Iranian students in American universities, and Sample 305 Iranian students in Iranian universities.

\section{Belonging}

Need to belong were assessed individual differences in contributors with the 10-item NTBS (Leary et al., 2008), explained earlier. Members ranked the degree to which each declaration in the NTBS was their attribute on a scale of 1 (not at all) to 7 (extremely). The sample of items were "If other people don't seem to accept me, The internal reliability of the NTBS was good $(\mathrm{a}=.83)($ Leary, Kelly, Cottrell, \& Schreindorfer, 2013).

\section{Result Common Method Variance}

The common method variance is expected to influence several assumed relationships in the Smart PLS path model since data on all model variables are gathered from individual respondents in a one-time survey. The researcher used Harman's (1976) single factor test to test the potential existence of common method bias. Common-method variance (CMV) is the incorrect "variance. that is attributable to the measurement method instead of to the concepts the appropriate measures are understood to describe" or consistently as "systematic error variance that is shared between variables calculated with and presented as a particular function of the same method and/or source". The Scientists utilized Harman's (1976) single-factor test. The first factor accounts for only $37.706 \%$ of the overall variance, which shows that likely CMV is did not have an impact on the discovery (Podsakoff \& Organ, 1986).

\section{Assessment of the Measurement Models}

The first step in evaluating measurement models or the composites estimated was to assess the reliability of the items by examining composites' loadings or correlation loads (Hair, Risher, Sarstedt, \& Ringle, 2019). As highlighted by Hair et al. (2019), a loading above 0.7 is recommended for each indicator as it ensures that the item communality is above 0.5 in the first stage and values above 0.8 or 0.9 in more complex stages of research. In contrast, a value below 0.6 reveals a lack of reliability (Nunnally \& Bernstein, 1994). Following this guiding principle, non-contributing items were dropped from all the scales. The second step was to evaluate internal consistency reliability. For this purpose, Cronbach's alpha, as a too conservative estimate of reliability, and Composite Reliability (CR), as a too liberal measure to estimate reliability, were considered (Hair et al., 2019; Sarstedt, Ringle, \& Hair, 2017). In addition, the newly introduced measure known as Rho_A (Dijkstra \& Henseler, 2015), was estimated. As elaborated by Hair et al. (2019), the reliability estimates should fall between 0.7 and 0.95. Next, convergent validity was assessed through evaluation of the Average Variance Extracted (AVE) metric, which should be above 0.5, as the indication of the establishment of this type of validity (Hair et al. 2017; Hair et al. 2019).

Table 1 displays the results of examining loadings, reliability estimates and AVE. As displayed in Table 1, all the loadings were above 0.708 , reliability estimates were within the accepted ranges, and AVEs were above 0.5. This implied the establishment of indicator reliability, internal consistency reliability, and convergent validity based on the latest guidelines proposed by Hair et al. (2019). The last step in evaluating measurement models was to assess 


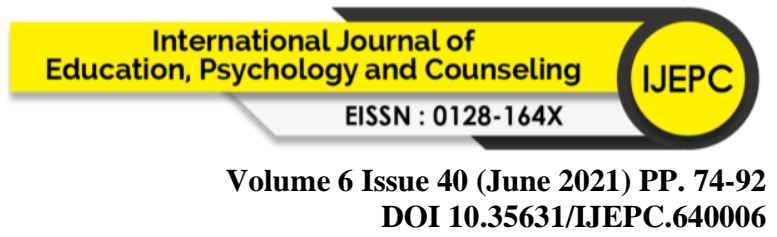

discriminant validity (Hair et al. 2019). For this purpose, the Heterotrait-Monotrait or HTMT (Dijkstra \& Henseler, 2015) were applied. Typically, for conceptually similar constructs, HTMT values above 0.9 would suggest the lack of discriminant validity between the constructs and with respect to the conceptually distinct constructs, HTMT values less than 0.85 are the indications of discriminant validity (Henseler, Ringle, \& Sarstedt, 2015). As displayed in Table 2 , all the HTMT values were less than 0.85 , implying the establishment of discriminant validity based on HTMT0.85 criterion.

Table 1. Loadings, Reliability Estimates, And Convergent Validity

\begin{tabular}{|c|c|c|c|c|c|c|c|}
\hline \multirow[t]{2}{*}{ Construct } & \multicolumn{3}{|c|}{ Loading factor } & \multirow{2}{*}{$\begin{array}{l}\text { Cronbach's } \\
\text { Alpha }\end{array}$} & \multirow[t]{2}{*}{ Rho-A } & \multirow[t]{2}{*}{$\mathrm{CR}$} & \multirow[t]{2}{*}{ AVE } \\
\hline & Item & $\begin{array}{l}\text { Initial } \\
\text { model }\end{array}$ & d Model & & & & \\
\hline Anxious & ANX1 & .334 & Deleted & .93 & .94 & .94 & .58 \\
\hline \multirow[t]{21}{*}{ Attachment } & ANX10 & .80 & .81 & & & & \\
\hline & ANX11 & .79 & .79 & & & & \\
\hline & ANX12 & .75 & .76 & & & & \\
\hline & ANX13 & .83 & .83 & & & & \\
\hline & ANX14 & .76 & .77 & & & & \\
\hline & ANX15 & .86 & .87 & & & & \\
\hline & ANX16 & .76 & .76 & & & & \\
\hline & ANX17 & .82 & .83 & & & & \\
\hline & ANX18 & .73 & .74 & & & & \\
\hline & ANX2 & .38 & Deleted & & & & \\
\hline & ANX3 & .25 & Deleted & & & & \\
\hline & ANX4 & .45 & Deleted & & & & \\
\hline & ANX5 & .59 & .58 & & & & \\
\hline & ANX6 & .70 & .70 & & & & \\
\hline & ANX7 & .74 & .74 & & & & \\
\hline & ANX8 & .62 & .61 & & & & \\
\hline & ANX9 & .52 & Deleted & & & & \\
\hline & AVO1 & .71 & .71 & .95 & .95 & .95 & .59 \\
\hline & AVO10 & -.004 & Deleted & & & & \\
\hline & AVO11 & .70 & .70 & & & & \\
\hline & AVO12 & .77 & .78 & & & & \\
\hline
\end{tabular}




$\begin{array}{lccc} & \text { AVO13 } & .74 & .74 \\ & \text { AVO14 } & .79 & .79 \\ & \text { AVO15 } & .83 & .83 \\ & \text { AVO16 } & .81 & .81 \\ & \text { AVO17 } & .82 & .82 \\ \text { Avoidant } & \text { AVO18 } & .81 & .81 \\ \text { Attachment } & \text { AVO2 } & .78 & .78 \\ & \text { AVO3 } & .85 & .85 \\ & \text { AVO4 } & .23 & \text { Deleted } \\ & \text { AVO5 } & .73 & .73 \\ & \text { AVO6 } & .11 & \text { Deleted } \\ & \text { AVO7 } & .73 & .73 \\ & \text { AVO8 } & .69 & .69 \\ & \text { AVO9 } & .73 & .73\end{array}$

$\begin{array}{lllllll}\text { IS1 } & .59 & \text { Deleted } & .93 & .93 & .93 & .51\end{array}$

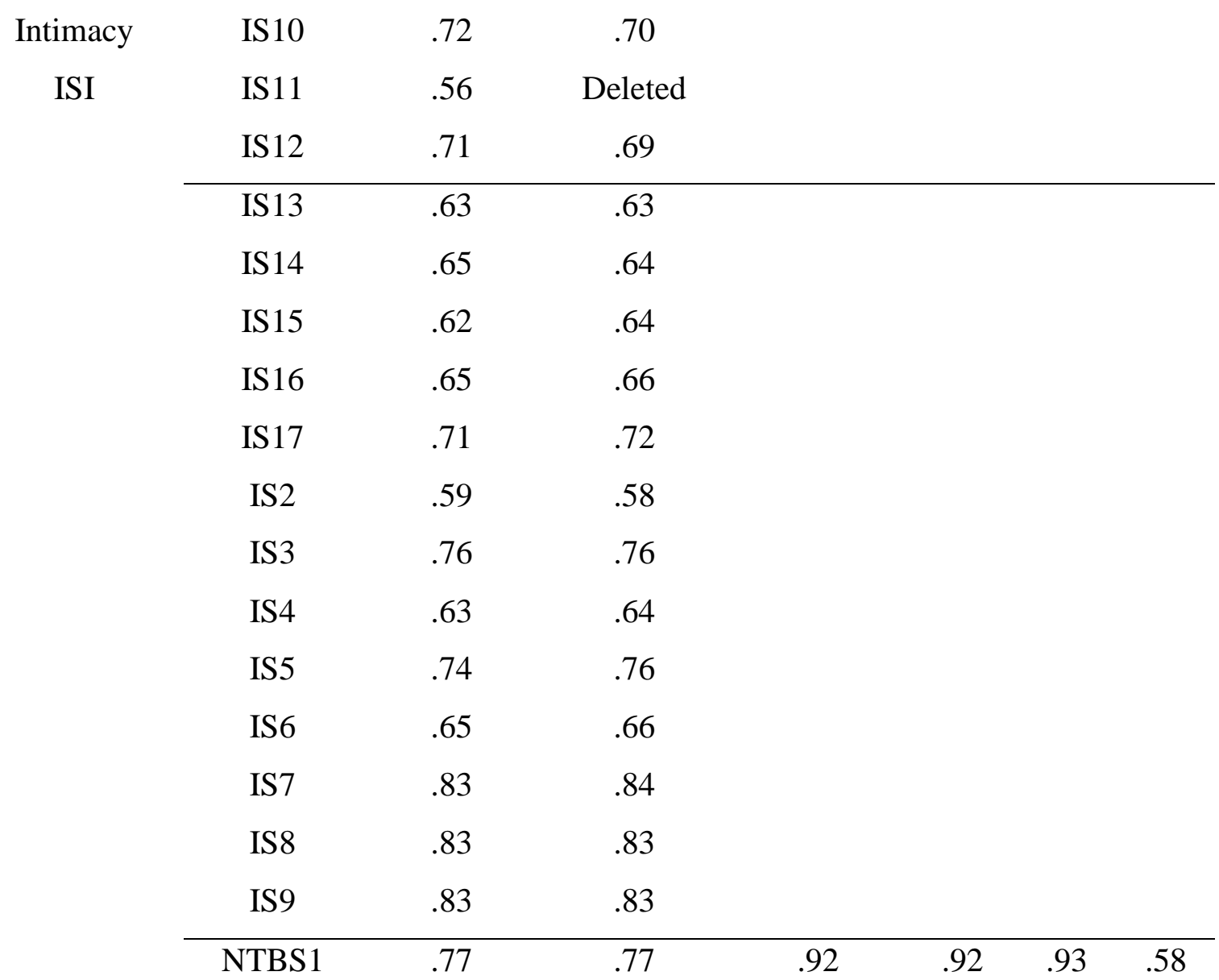




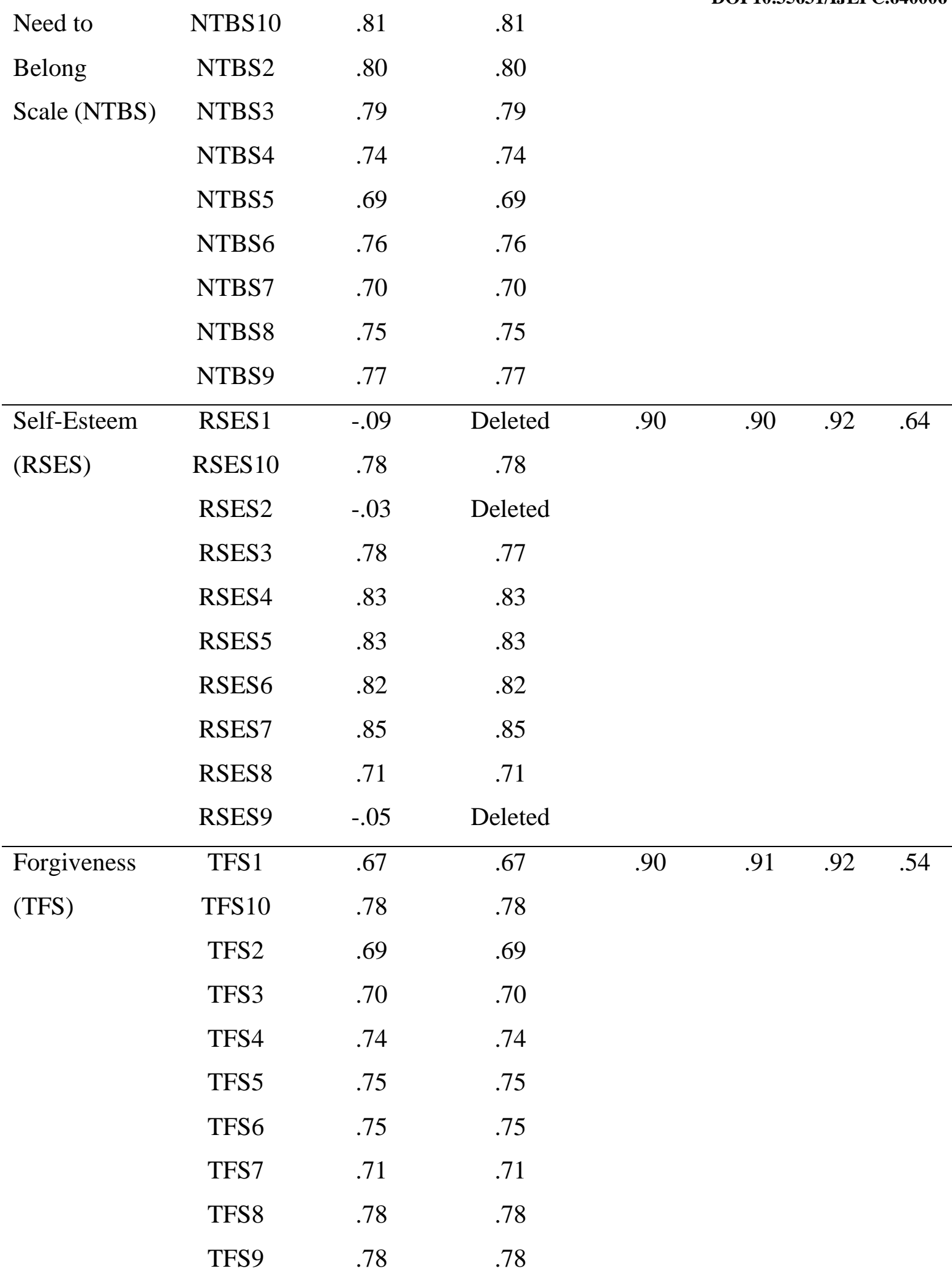


Table 2. Correlation of latent variables and discriminant Validity HTMT

\begin{tabular}{lcccccc}
\hline & ANXA & AVOA & TFS & IS & NTBS & SE \\
\hline ANXA & & & & & & \\
AVODA & .13 & & & & & \\
TFS & .36 & .43 & & & & \\
IS & .13 & .48 & .73 & & & \\
NTBS & .29 & .44 & .75 & .59 & & \\
SE & .31 & .46 & .65 & .46 & .57 & \\
\hline
\end{tabular}

ANXA: Anxious Attachment, AVOA: Avoidant Attachment, TFS: Forgiveness, Is: Intimacy, NTBS: Belonging, SE: self-Esteem.

\section{Assessment of the Structural Model}

When construct assessments are confirmed and genuinely reliable and valid, the subsequent phase focus on the measuring of the structural model results (Hair et al., 2014). The structural model result needs to analyse the predictive abilities of the model and the relations between the constructs. The key criteria for evaluating the structural model in PLS-SEM are examined the measurement of collinearity among the predictor construct, the significance of the path coefficients, the level of the R2 values, and the predictive relevance (Q2).

The findings of boot strapping technique (Table 4.21) demonstrate a p-value for each path. All structural model contacts were significant considering a $p$ - value $=0.05$. In the model both IVs had a significant a negative coefficient which means, lower level of variables will tend to accomplish a marital satisfaction. More specifically, the decomposition of the $\mathrm{R}^{2}$ value shows that forgiveness explained 67 percent towards avoidant attachment, anxious attachment, intimacy, self-esteem, and belonging, which indicate that 67 percent of the variance in this construct explained. Furthermore, $\mathrm{R}^{2}$ values for intimacy 21 percent, belonging 22 percent and self-esteem 24 percent. Typically, the endogenous latent variables are categorized as considerable, moderate or weak based on $\mathrm{R}^{2}$ values of $0.67,0.33$ or 0.19 , respectively (Chin 2008). Since in the primary dependent variable in this model which was forgiveness as we can see here, $\mathrm{R}^{2}$ value for the forgiveness construct was 0.67 which indicated that 67 percent of the variance in this construct is explained by factors: anxious attachment, avoidant attachment, intimacy, self-esteem, and belonging and it was above 50 percent indicated perfect fitness in the model For calculating of predictive relevance of the recommended model, the blindfolding system with the cross-validated redundancy method (Stone-Geisser's Q2 value) was utilized. As there were 435 respondents, an omission distance of $\mathrm{D}=7$ was studied for this research. This method for model predictability was measured individually. The findings of the construct cross-validated redundancy estimation are applied to demonstrate that the forecast importance for a dependent construct. The value of Q2 should be above zero (0). The outcomes revealed that the Q2 values of forgiveness (0.347) intimacy (0.103), belonging (0.122), self-esteem (0.146) is well above the threshold (zero) requirement which indicates that the model has predictive relevance for these constructs. 
Volume 6 Issue 40 (June 2021) PP. 74-92

DOI 10.35631/IJEPC.640006

Table3. Test of The Total Effects Using Bootstrapping

\begin{tabular}{lrrrr}
\hline \multicolumn{1}{c}{ PATH } & \multicolumn{1}{c}{$\boldsymbol{\beta}$} & SE & T value & $\begin{array}{c}\text { P } \\
\text { Values }\end{array}$ \\
\hline Anxious attachment -> Forgiveness & -.08 & .03 & 2.766 & 0.003 \\
Anxious attachment -> Intimacy & -.06 & .04 & 1.344 & 0.089 \\
Anxious attachment -> Belonging & -.22 & .03 & 5.765 & 0.000 \\
Anxious attachment -> Self Esteem & -.24 & .04 & 5.862 & 0.000 \\
Avoidance attachment -> Forgiveness & .02 & .03 & 0.717 & 0.237 \\
Avoidance attachment -> Intimacy & -.45 & .04 & 11.126 & 0.000 \\
Avoidance attachment -> Need to & -.39 & .03 & 10.359 & 0.000 \\
Belong & & & & \\
Avoidance attachment -> Self Esteem & -.40 & .03 & 10.343 & 0.000 \\
Intimacy -> Forgiveness & .29 & .04 & 6.957 & 0.000 \\
Need to Belong -> Forgiveness & .30 & .03 & 7.754 & 0.000 \\
Self-Esteem -> Forgiveness & .20 & .03 & 5.563 & 0.000 \\
Anxious attachment -> Forgiveness & -.08 & .03 & 2.766 & 0.003 \\
Avoidant attachment -> Forgiveness & .02 & .03 & 0.717 & 0.237 \\
\hline
\end{tabular}

\section{Evaluating Significance and Relevance of the Mediation Model}

To recognize a familiar connection by discovering the basic method or procedure by which one variable affects another variable across a mediator variable, mediation assessments are used (Cohen, Cohen, West, \& Aiken, 2013).

Mediation evaluation was done based on to (Hair, Sarstedt, Hopkins, \& Kuppelwieser, 2014) and table 3 represents the indirect effect of anxious and avoidant attachment on forgiveness through intimacy, self-esteem and belonging and indirect effect of intimacy, empathy, selfesteem and belonging on marital satisfaction through forgiveness using bootstrapping. According to these results, intimacy, self-esteem and belonging significantly mediated the relationship between anxious, avoidant attachment and forgiveness. In the case of anxious attachment and forgiveness via intimacy there is no mediation.

The findings of direct and indirect effects; are shown in the Table 4 Findings of indirect effect anxious attachment and forgiveness via intimacy, self-esteem and belonging indicates that intimacy, belonging) and self-esteem had relatively significant mediation and in the case of intimacy there is no mediation. Findings of indirect effect avoidant attachment and forgiveness via, intimacy, belonging and self-esteem indicate that intimacy, belonging and self-esteem had relatively significant mediation.

In accordance with these outcomes, it was created that both the direct and indirect effects of anxious attachment on forgiveness have been statistically meaningful. Therefore, it may be asserted that in this study, belonging, and self-esteem partially mediates the relationship between anxious attachment on forgiveness. In case of anxious attachment on forgiveness with the mediating role of intimacy, the direct effect of anxious attachment on intimacy was 


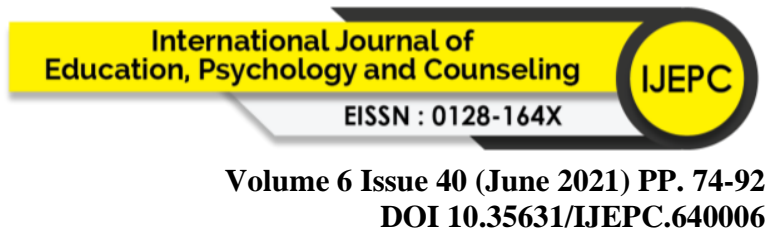

nonsignificant so there is no mediation between anxious attachment and forgiveness via intimacy.

According to these findings, it was found that the direct effect of avoidance on forgiveness was not statistically significant. In contrast, the indirect effect of avoidance attachment on forgiveness was statistically significant. Therefore, it may be asserted that in this study, intimacy, belonging, and self-esteem fully mediates the relationship between avoidance attachment on forgiveness. Figure 2 displays the final model after taking all the steps in evaluating measurement models and the structural model proposed by Hair et al. (2019).

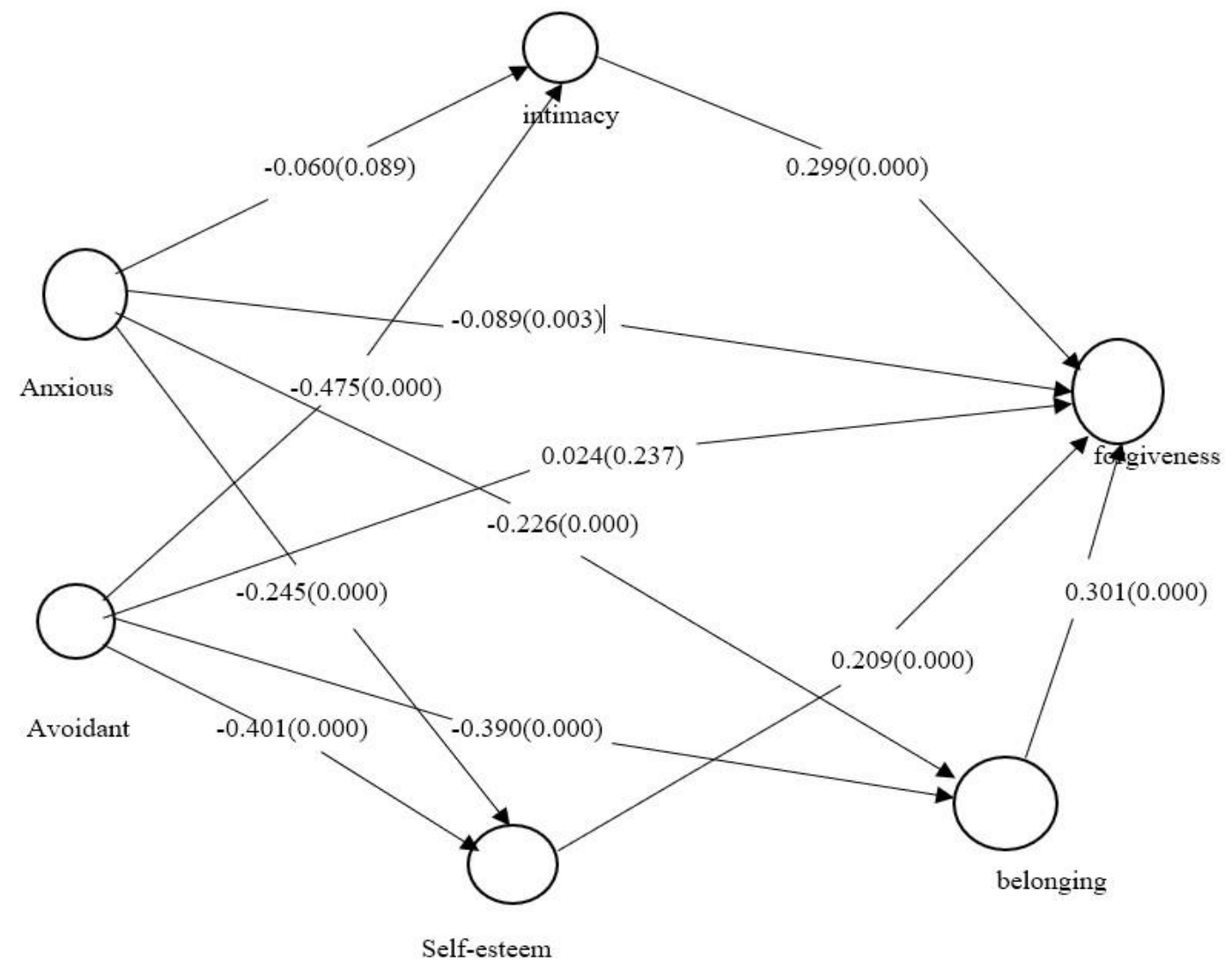

Figure 2. Path Model Discussion And Conclusion

Table 4. Summary of Model

\begin{tabular}{lcccccc}
\hline \multirow{2}{*}{ path } & \multicolumn{2}{c}{ Direct effect } & \multicolumn{2}{c}{ Indirect effect } & \multirow{2}{*}{ Result } \\
\cline { 2 - 5 } & $\beta$ & P Values & $\beta$ & P Values & \\
\cline { 2 - 5 } AnxA-> NTB -> F & -.08 & .003 & -.07 & 0.000 & Partially \\
AnxA -> SE -> F & & & -.05 & 0.000 & Mediation \\
AnxA-> Intimacy -> F & -.08 & .003 & -.02 & 0.10 & \multirow{2}{*}{ No Mediation } \\
AvoA-> Intimacy -> F & .02 & .23 & -.14 & 0.000 & Partially \\
AvoA -> NTB -> F & & & -.12 & 0.000 & Mediation \\
AvoA-> SE -> F & & & -.08 & 0.000 &
\end{tabular}




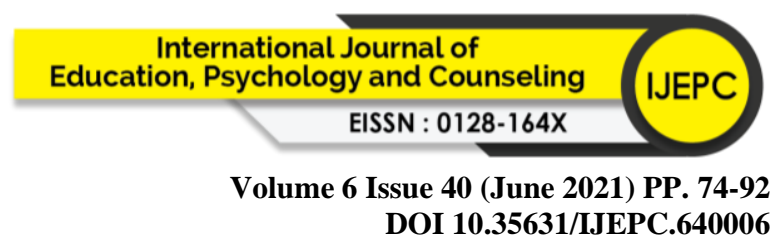

The results revealed a path wherein anxious attachment led to reduced forgiveness through the lack of belonging and self-esteem and avoidant attachment through lack of intimacy, belonging, self-esteem. Attachment theory is a strong candidate as a framework for understanding when and why people may respond to a transgression with forgiveness, because not only is it fundamental to our understanding of how we negotiate interpersonal relationships, but also predicts state variables associated with forgiveness. furthermore, (Hall, Fujikawa, Halcrow, Hill, \& Delaney, 2009) found that unforgiveness was positively correlated with both avoidant attachment and anxious attachment, suggesting a link between forgiveness, attachment.

By confirming the mediating role of intimacy, belonging, self-esteem, the path model indicates that attachment and forgiveness can be predicted through intimacy, belonging, self-esteem, and that forgiveness can be improved through intimacy, belonging, self-esteem even when an insecure attachment is present. Previous studies have found that mediation variables can have therapeutic value as they enable environmental interventions (Baron \& Kenny, 1986) and intimacy, belonging, self-esteem can be developed and promoted through training (Bagarozzi, 2014; McKay \& Fanning, 2016; Walton \& Brady, 2020). The importance of the roles of intimacy, belonging, self-esteem has been emphasized in the relationship between attachment and forgivingness. In research with college students, it was found that anxious attachment was strongly related to belonging and self-esteem and avoidant attachment to a lack of intimacy and belonging and self-esteem (Burnette et al., 2009; Chung \& Lee, 2014).

People with avoidant attachment might likely result in a shortage of belongingness and lack of intimacy within an individual person. Chen et al., 2015 in their study among young people discovered the positive link between insecure attachment and the social detachment. Therefore, In the other experiments, considerable-level relationships were discovered between attachment styles and need for belongingness and intimacy (Greenwood \& Long, 2011; Venta, Mellick, Schatte, \& Sharp, 2014). And also individual who have les desire for belonging and intimacy shows less likelihood of expanding forgiveness to wrongdoers (Barnes et al., 2010). A comparison of the results with those of other findings confirms that individuals with greater concentrations of avoidance and anxiety were correlated with reduce levels of self-esteem. growing individuals' self-esteem may support the enhancement of their forgiveness trait (Brown \& Phillips, 2005; Eaton, Struthers, \& Santelli, 2006; J. H. Hall \& Fincham, 2005; Yalcin et al., 2017)

In particular, the path model of this study leading from attachment to forgiveness can be applied to either married men or married couple, as evidenced by the overall structure, path coefficients, covariances, and error variances. My work has implications for education, training, and therapy.

This study has some limitations. First, the subjects of this study were all women; therefore, caution is required when applying these results to other groups. Future research should compare our results to those of investigations that include couples (both men and women), men, separated and divorced people, and individuals from other countries and cultures to realize higher generalization. 


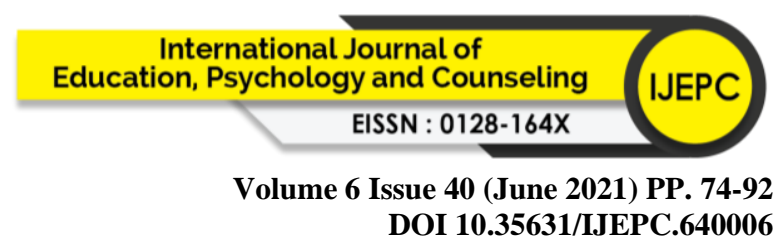

Second, although the model enhances the understanding of how attachment, intimacy, belonging, self-esteem, are associated with forgiveness, the model does not explain all factors that contribute to forgiveness. Attachment is a strong predictor of forgiveness; however, it is important to investigate other variables that contribute to forgiveness and can be addressed in therapy to improve couples' relationships.

The next limitation relevant to self-reported instruments was possible to have occurred, including participants' lack of cooperation in providing information about themselves. All these adapted questionnaires were based on the theories and findings of developed countries. As Iran is a developing country, so due to change in their sources, infrastructure, different cultural results might not be the same as compared with hypothesizing.

\section{Acknowledgment}

The authors would like to thank the University of Malaya for support of this work.

\section{References}

Ainsworth, M. (1978). D. S., Blehar, M. C., Waters, E., \&Wall, S.

Ainsworth, M. D. S., Blehar, M. C., Waters, E., \& Wall, S. (1978). Patterns ofattachment. A Psychological Study of the Strange Situation. Hillsdale, NY: Erlbaum.

Amani, A., Sohrabi, A., Bagheri, L., \& Nasisi Hains, G. (2017). The effectiveness of Adlerian group counseling on couples' intimacy and interpersonal forgiveness. Family Counseling \& Psychotherapy, 7(1), 45-64.

Askari, Z. (2016). Forgiveness and its relationship with marital satisfaction: a sectional study. The International Journal of Indian Psychology, Volume 3, Issue 3, No. 10, 84.

Bagarozzi, D. A. (2014). Enhancing intimacy in marriage: A clinician's guide. routledge.

Barnes, C. D., Carvallo, M., Brown, R. P., \& Osterman, L. (2010). Forgiveness and the need to belong. Personality and Social Psychology Bulletin, 36(9), 1148-1160.

Bartholomew, K., \& Horowitz, L. M. (1991). Attachment styles among young adults: a test of a four-category model. Journal of Personality and Social Psychology, 61(2), 226.

Berry, J. W., Worthington, E. L., O’Connor, L. E., Parrott, L., \& Wade, N. G. (2005). Forgivingness, vengeful rumination, and affective traits. Journal of Personality, 73(1), 183-226.

Bono, G., McCullough, M. E., \& Root, L. M. (2008). Forgiveness, feeling connected to others, and well-being: Two longitudinal studies. Personality and Social Psychology Bulletin, 34(2), 182-195.

Bowlby, J. (1969). Attachment and Loss: Attachment; John Bowlby. Basic Books.

Bowlby, J. (1977). The making and breaking of affectional bonds. II. Some principles of psychotherapy. The fiftieth Maudsley Lecture. The British Journal of Psychiatry, 130(5), 421-431.

Bowlby, J. (1980). Attachment and loss: Loss, sadness and depression (Vol. 3). New York: Basic Books.

Bowlby, J. (1982). Attachment and loss, vol. I: Attachment, (Original work published 1969). Basic Books.[CBN].

Braithwaite, S. R., Selby, E. A., \& Fincham, F. D. (2011). Forgiveness and relationship satisfaction: Mediating mechanisms. Journal of Family Psychology, 25(4), 551.

Brown, R. P., \& Phillips, A. (2005). Letting bygones be bygones: Further evidence for the validity of the Tendency to Forgive scale. Personality and Individual Differences, 38(3), 627-638. 
Burnette, J. L., Davis, D. E., Green, J. D., Worthington, E. L., \& Bradfield, E. (2009). Insecure attachment and depressive symptoms: The mediating role of rumination, empathy, and forgiveness. Personality and Individual Differences, 46(3), 276-280.

Chen, C., Hewitt, P. L., \& Flett, G. L. (2015). Preoccupied attachment, need to belong, shame, and interpersonal perfectionism: An investigation of the perfectionism social disconnection model. Personality and Individual Differences, 76, 177-182.

Chen, X., Colón, X., \& Barrow, C. (2020). 129-Attachment and Emotion Dysregulation as Predictors of Interpersonal Problems, Friendship Satisfaction, and Romantic Relationship Maintenance.

Chung, M. S., \& Lee, K. J. (2014). A path-analytic study of associations between attachment, rumination, empathy, and forgiveness. Journal of Special Education and Rehabilitation Science, 53(3), 193-209.

Cohen, J., Cohen, P., West, S. G., \& Aiken, L. S. (2013). Applied multiple regression/correlation analysis for the behavioral sciences. Routledge.

Collins, N. L., \& Allard, L. M. (2001). Cognitive representations of attachment: The content and function of working models. Blackwell Handbook of Social Psychology: Interpersonal Processes, 2, 60-85.

Collins, N. L., \& Feeney, B. C. (2000). A safe haven: An attachment theory perspective on support seeking and caregiving in intimate relationships. Journal of Personality and Social Psychology, 78(6), 1053.

Dijkstra, T. K., \& Henseler, J. (2015). Consistent partial least squares path modeling. MIS Quarterly, 39(2), 297-316.

Downey, G., \& Feldman, S. I. (1996). Implications of rejection sensitivity for intimate relationships. Journal of Personality and Social Psychology, 70(6), 1327.

Eaton, J., Struthers, C. W., \& Santelli, A. G. (2006). Dispositional and state forgiveness: The role of self-esteem, need for structure, and narcissism. Personality and Individual Differences, 41(2), 371-380.

Feeney, J. A., \& Karantzas, G. C. (2017). Couple conflict: insights from an attachment perspective. Current Opinion in Psychology, 13, 60-64.

Fehr, R., Gelfand, M. J., \& Nag, M. (2010). The road to forgiveness: a meta-analytic synthesis of its situational and dispositional correlates. Psychological Bulletin, 136(5), 894.

Fincham, F. D., \& Beach, S. R. H. (2002). Forgiveness in marriage: Implications for psychological aggression and constructive communication. Personal Relationships, 9(3), 239-251.

Fincham, F. D., Hall, J., \& Beach, S. R. H. (2006). Forgiveness in marriage: Current status and future directions. Family Relations, 55(4), 415-427.

Greenwood, D. N., \& Long, C. R. (2011). Attachment, belongingness needs, and relationship status predict imagined intimacy with media figures. Communication Research, 38(2), $278-297$.

Gulzar, S. (2018). Attachment, Gender Role Conflict and Intimate Relationship in University Students. University of Management and Technology, Lahore.

Hair, J. F., Risher, J. J., Sarstedt, M., \& Ringle, C. M. (2019). When to use and how to report the results of PLS-SEM. European Business Review.

Hair Jr, J. F., Sarstedt, M., Hopkins, L., \& Kuppelwieser, V. G. (2014). Partial least squares structural equation modeling (PLS-SEM). European Business Review.

Hall, J. H., \& Fincham, F. D. (2005). Self-forgiveness: The stepchild of forgiveness research. Journal of Social and Clinical Psychology, 24(5), 621-637. 


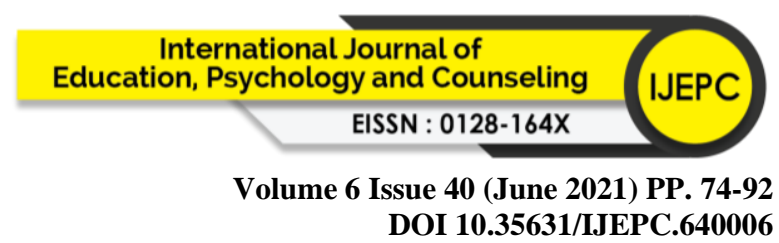

Hall, T. W., Fujikawa, A., Halcrow, S. R., Hill, P. C., \& Delaney, H. (2009). Attachment to God and implicit spirituality: Clarifying correspondence and compensation models. Journal of Psychology and Theology, 37(4), 227-244.

Henseler, J. (2018). Partial least squares path modeling: Quo vadis? Quality \& Quantity, 52(1), $1-8$.

Henseler, J., Ringle, C. M., \& Sarstedt, M. (2015). A new criterion for assessing discriminant validity in variance-based structural equation modeling. Journal of the Academy of Marketing Science, 43(1), 115-135.

Hirst, S. L., Hepper, E. G., \& Tenenbaum, H. R. (2019). Attachment dimensions and forgiveness of others: A meta-analysis. Journal of Social and Personal Relationships, 36(11-12), 3960-3985.

Hong, W., Liu, R.-D., Ding, Y., Oei, T. P., Fu, X., Jiang, R., \& Jiang, S. (2020). Self-esteem moderates the effect of compromising thinking on forgiveness among Chinese early adolescents. Frontiers in Psychology, 11, 104.

KHOJASTEH, M. R., \& Koraei, A. (2010). Evaluation of Psychometric Properties of the Transgression-Related Interpersonal Motivations Inventory.

Langman, L., \& Chung, M. C. (2013). The relationship between forgiveness, spirituality, traumatic guilt and posttraumatic stress disorder (PTSD) among people with addiction. Psychiatric Quarterly, 84(1), 11-26.

Leary, M. R., Kelly, K. M., Cottrell, C. A., \& Schreindorfer, L. S. (2013). Construct validity of the need to belong scale: Mapping the nomological network. Journal of Personality Assessment, 95(6), 610-624.

Maslow, A. H. (1943). A theory of human motivation. Psychological Review, 50(4), 370.

Maslow, A. H. (1970). Personalitv.

McKay, M., \& Fanning, P. (2016). Self-esteem: A proven program of cognitive techniques for assessing, improving, and maintaining your self-esteem. New Harbinger Publications.

Mikulincer, M., \& Florian, V. (2001). Attachment style and affect regulation: Implications for coping with stress and mental health. Blackwell Handbook of Social Psychology: Interpersonal Processes, 535-557.

Mikulincer, M., Shaver, P. R., Bar-On, N., \& Sahdra, B. K. (2014). Security enhancement, selfesteem threat, and mental depletion affect provision of a safe haven and secure base to a romantic partner. Journal of Social and Personal Relationships, 31(5), 630-650.

Murray, S. L., \& Holmes, J. G. (2008). The commitment-insurance system: Self-esteem and the regulation of connection in close relationships. Advances in Experimental Social Psychology, 40, 1-60.

Nunnally, J. C., \& Bernstein, I. H. (1994). Validity. Psychometric Theory, 3, 99-132.

Orth, U., \& Robins, R. W. (2019). Development of self-esteem across the lifespan.

Otway, L. J., \& Carnelley, K. B. (2013). Exploring the associations between adult attachment security and self-actualization and self-transcendence. Self and Identity, 12(2), 217230.

Pielage, S. B., Luteijn, F., \& Arrindell, W. A. (2005). Adult attachment, intimacy and psychological distress in a clinical and community sample. Clinical Psychology \& Psychotherapy: An International Journal of Theory \& Practice, 12(6), 455-464.

Podsakoff, P. M., \& Organ, D. W. (1986). Self-reports in organizational research: Problems and prospects. Journal of Management, 12(4), 531-544.

Riek, B. M., \& Mania, E. W. (2012). The antecedents and consequences of interpersonal forgiveness: A meta-analytic review. Personal Relationships, 19(2), 304-325. 


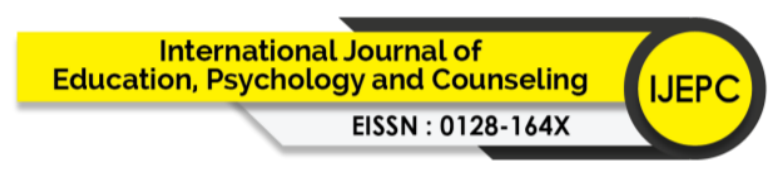

Volume 6 Issue 40 (June 2021) PP. 74-92

DOI 10.35631/IJEPC.640006

Rosenberg, M. (1965). Rosenberg self-esteem scale (RSE). Acceptance and Commitment Therapy. Measures Package, 61(52), 18.

Sampthirao, P. (2016). Self-concept and interpersonal communication. The International Journal of Indian Psychology, 3(3), 177-189.

Sarstedt, M., Ringle, C. M., \& Hair, J. F. (2017). Treating unobserved heterogeneity in PLSSEM: A multi-method approach. In Partial least squares path modeling (pp. 197217). Springer.

Satici, S. A., \& Tekin, E. G. (2016). Psychometric properties of the general belongingness scale in Turkish youth. Current Psychology, 35(4), 625-631.

Shapurian, R., Hojat, M., \& Nayerahmadi, H. (1987). Psychometric characteristics and dimensionality of a Persian version of Rosenberg Self-esteem Scale. Perceptual and Motor Skills, 65(1), 27-34.

Simpson, J. A., \& Rholes, W. S. (2017). Adult attachment, stress, and romantic relationships. Current Opinion in Psychology, 13, 19-24.

Smart Richman, L., \& Leary, M. R. (2009). Reactions to discrimination, stigmatization, ostracism, and other forms of interpersonal rejection: a multimotive model. Psychological Review, 116(2), 365.

Strelan, P., Karremans, J. C., \& Krieg, J. (2017). What determines forgiveness in close relationships? The role of post-transgression trust. British Journal of Social Psychology, 56(1), 161-180.

Tiwari, G. K., Pandey, R., Parihar, P., \& Rai, P. K. (2020). Understanding the mediating role of self-esteem between the relationship of self-forgiveness and human flourishing.

Toussaint, L. L., Worthington, E. L., Williams, D. R., \& Webb, J. R. (2019). Forgiveness and Physical Health. Handbook of Forgiveness, 178-187.

Venta, A., Mellick, W., Schatte, D., \& Sharp, C. (2014). Preliminary evidence that thoughts of thwarted belongingness mediate the relations between level of attachment insecurity and depression and suicide-related thoughts in inpatient adolescents. Journal of Social and Clinical Psychology, 33(5), 428-447.

Walker, A. J., \& Thompson, L. (1983). Intimacy and intergenerational aid and contact among mothers and daughters. Journal of Marriage and the Family, 841-849.

Walton, G. M., \& Brady, S. T. (2020). The social-belonging intervention. Handbook of Wise

Interventions: How Social Psychology Can Help People Change. The Guilford Press. Http://Gregorywaltonstanford. Weebly.

Com/Uploads/4/9/4/4/49448111/Waltonbrady2019. Pdf.

Wazid, S. W., \& Shahnawaz, M. G. (2017). Relationship quality as mediator of forgiveness and psychological well-being among transgressors in romantic relationships. Psychological Studies, 62(2), 200-208.

Wieselquist, J. (2009). Interpersonal forgiveness, trust, and the investment model of commitment. Journal of Social and Personal Relationships, 26(4), 531-548.

Worthington Jr, E. L., \& Sandage, S. J. (2016). Forgiveness in group interventions.

Yalcin, S. B., Kavakli, M., \& Kesici, S. (2017). The Predictive Power of Undergraduates' Personality Traits and Self-Esteem Regarding Their Forgiveness. Online Submission, 8(18), 13-20. 